\title{
Quality of primary care for resettled refugees in the Netherlands with chronic mental and physical health problems: a cross-sectional analysis of medical records and interview data
}

\author{
Marije A van Melle ${ }^{1 *}$, Majda Lamkaddem¹, Martijn M Stuiver ${ }^{2}$, Annette AM Gerritsen³, Walter LJM Devillée,5,6
} and Marie-Louise Essink-Bot ${ }^{1}$

\begin{abstract}
Background: A high prevalence of mental and physical ill health among refugees resettled in the Netherlands has been reported. With this study we aim to assess the quality of primary healthcare for resettled refugees in the Netherlands with chronic mental and non-communicable health problems, we examined: a) general practitioners' (GP) recognition of common mental disorders (CMD) (depression and anxiety, and post-traumatic stress disorder (PTSD) symptoms); b) patients' awareness of diabetes type II (DMII) and hypertension (HT); and c) GPs' adherence to guidelines for CMD, DMII and HT.

Methods: From 172 refugees resettled in the Netherlands, interview data (2010-2011) and medical records ( $n=106)$, were examined. Inclusion was based on medical record diagnoses for DMII and HT, and on questionnaire-based CMD measures (Hopkins Symptom Checklist for depression and anxiety; Harvard Trauma Questionnaire for PTSD). GP recognition of $C M D$ was calculated as the number of $C M D$ cases registered in the medical record compared with those found in interviews. Patient awareness of HT and DMII was scored as the percentage of subjects diagnosed by the GP who reported their condition during the interview. GPs' adherence to guidelines for CMD, DMII and HT was measured using established indicators.
\end{abstract}

Results: We identified 37 resettled refugees with CMD of which 18 (49\%) had been recognised by the GP. We identified 16 refugees with DMII and 14 with $\mathrm{HT}$ from the medical record; 24 (80\%) were aware of their condition. Thirty-five out of these 53 (66\%) resettled refugees with chronic mental and non-communicable disorders received guideline-adherent treatment.

Conclusion: This study shows that awareness in resettled refugees of GP diagnosed DMII and HT is high, whereas GP recognition of $\mathrm{CMD}$ and overall guideline adherence are moderate.

Keywords: Chronic disease, Mental health, Refugees, Quality of care, Primary care

\section{Background}

According to the United Nations Refugee Agency there are approximately 75,000 refugees (defined as "persons granted a complementary form of protection and those granted temporary protection") living in the Netherlands [1]. When granted a residence permit, asylum seekers become permit holders and full resettlement is made

\footnotetext{
*Correspondence: m.a.vanmelle-2@umcutrecht.nl

'Department of Public Health, Academic Medical Center, University of Amsterdam, Amsterdam, The Netherlands

Full list of author information is available at the end of the article
}

possible. Then, resettled refugees are entitled to the same health care as any other Dutch citizen. Prior to becoming a permit holder, asylum seekers reside mainly in reception centres located throughout the Netherlands. Access to health care is broad but regulated in a different way: i.e. the first contact point with health services is the telephone line of the Asylum seekers' Healthcare Centre (GCA), instead of the general practitioner (GP). The GCA is in charge of directing the health matter to a GP or another primary healthcare provider. With a (temporary or definitive) residence permit, resettled refugees (or permit 
holders) can make direct contact with their GP (as do the general Dutch population). In this transition information from the medical file is transferred to the GP. Generally, the GP plays a central role as a first contact point in the organisation and access to healthcare services in the Netherlands. Access to most specialist health services can be gained through referral from the GP.

In 2003-2004, the first wave of this study (T1) on health and healthcare utilisation of asylum seekers and permit holders in the Netherlands was conducted among 410 respondents from Afghanistan, Iran and Somalia [2]. The second wave (T2) evolved subsequently and was conducted in 2010-2011 among 172 of those latter respondents, all of whom had meanwhile obtained a permit. The data collection used in the second wave was an exact copy of the first.

Results of the first assessment (T1) showed a high prevalence of psychiatric disorders, including depression (68.1\%), general anxiety (39.4\%) and post-traumatic stress disorder (PTSD; 28.1\%). These numbers far exceeded worldwide prevalence data (depression 5\% [3], anxiety $10 \%$ and PTSD $6.8 \%$ [4]), which is comparable to the current prevalence in the Dutch population (depression: $6.1 \%$ (5), anxiety $10.1 \%$, and PTSD 1.3\%) [5]. This earlier study confirmed results from international studies on refugees in Western countries [6-9].

Guideline adherence for CMD the Netherlands is 27$58 \%$ [10], however previous research showed that refugees with a mental disorder are less likely to receive adequate care and/or a referral to mental health care services than the general population, even when controlled for socioeconomic factors [11].

Chronic non-communicable conditions are prevalent among refugees resettled in Western countries [12-14]. Depending on the populations and definitions, prevalence as high as $15.5 \%$ has been reported for diabetes type II (DMII) and 42\% for hypertension (HT) [15], whereas in the native Dutch population this is $4.1 \%$ and $51 \%$, respectively [16]. Among Dutch populations of African descent prevalences of DMII and HT are $46 \%$ and $38 \%$ respectively [17]. Guideline adherence for DMII and HT in the Netherlands is $41-59 \%$ and $60 \%$ respectively [10]; however previous studies found low diabetes control and low hypertension control in migrant populations, suggesting inadequate quality of care in these groups $[18,19]$. In addition, one study found low control rates for diabetes among refugee populations, suggesting inadequate quality of care for members of this group [19]. However, this topic has not yet been thoroughly investigated.

Based on the relatively high disease burden of resettled refugees in the Netherlands, and the sparse evidence on primary healthcare for resettled refugees, this study aims to examine the quality of GP care for resettled refugees in the Netherlands. We focused on patients with DMII,
HT and symptoms of a common mental disorder (CMD) because of the relatively high prevalence of these health problems in our research sample. Only data from the second wave of the study (T2) were used. We examined both interview data and GP medical records. Quality of care can be assessed in several ways. We chose to limit the assessment of quality of care to the performance of the practitioner [20] through guideline adherence. Rather than limiting the present study to the investigation of guideline adherence by GPs, we also addressed the extent to which the GP recognised or diagnosed the three health complaints (GP-recognition) that are the focus of this study and the extent to which resettled refugees were aware of their own chronic disease (patient awareness).

\section{Methods}

\section{General study design}

This study is a cross-sectional analysis of healthcare medical records and interview data, embedded in a prospective two-wave longitudinal cohort study on health and healthcare use by refugees in the Netherlands.

\section{Setting and study population}

All 410 respondents of the first wave of the study (T1; 2003-2004) (for details on recruitment and methods see $[21,22])$ were considered eligible for the second wave of this study (T2). Figure 1 presents an overview of the data collection process. Of those 410 original respondents, 7 years later, 282 had a valid address in the Netherlands. Of those 282 respondents, 172 participated in the second wave of the study (response $=61 \%$, retention rate $=42 \%$ ). All respondents in the second wave had meanwhile become permit holders (Figure 1).

The 172 participants at T2 were also asked for their permission to collect data from their GP medical records on the year preceding the interview date. 130 participants signed the informed consent (130/172, 81\%). Finally, 106 (106/130, 82\%) complete medical records were made available from several GP practices.

\section{Data collection}

This study focused on CMD, DMII and HT because of the widely accepted quality indicators for treatment and because of the high prevalence of these conditions among the present study population. Figure 2 shows the process of patient identification, data extraction and analysis for CMD, DMII and HT.

\section{Patient interviews}

Only interviews conducted at T2 were used for the present study. All interviews were questionnaire based and conducted in the language of choice of the participants (Dutch, Dari, Pashto, Farsi or Somali). Interviewers were matched on gender and ethnic background. The questionnaire 


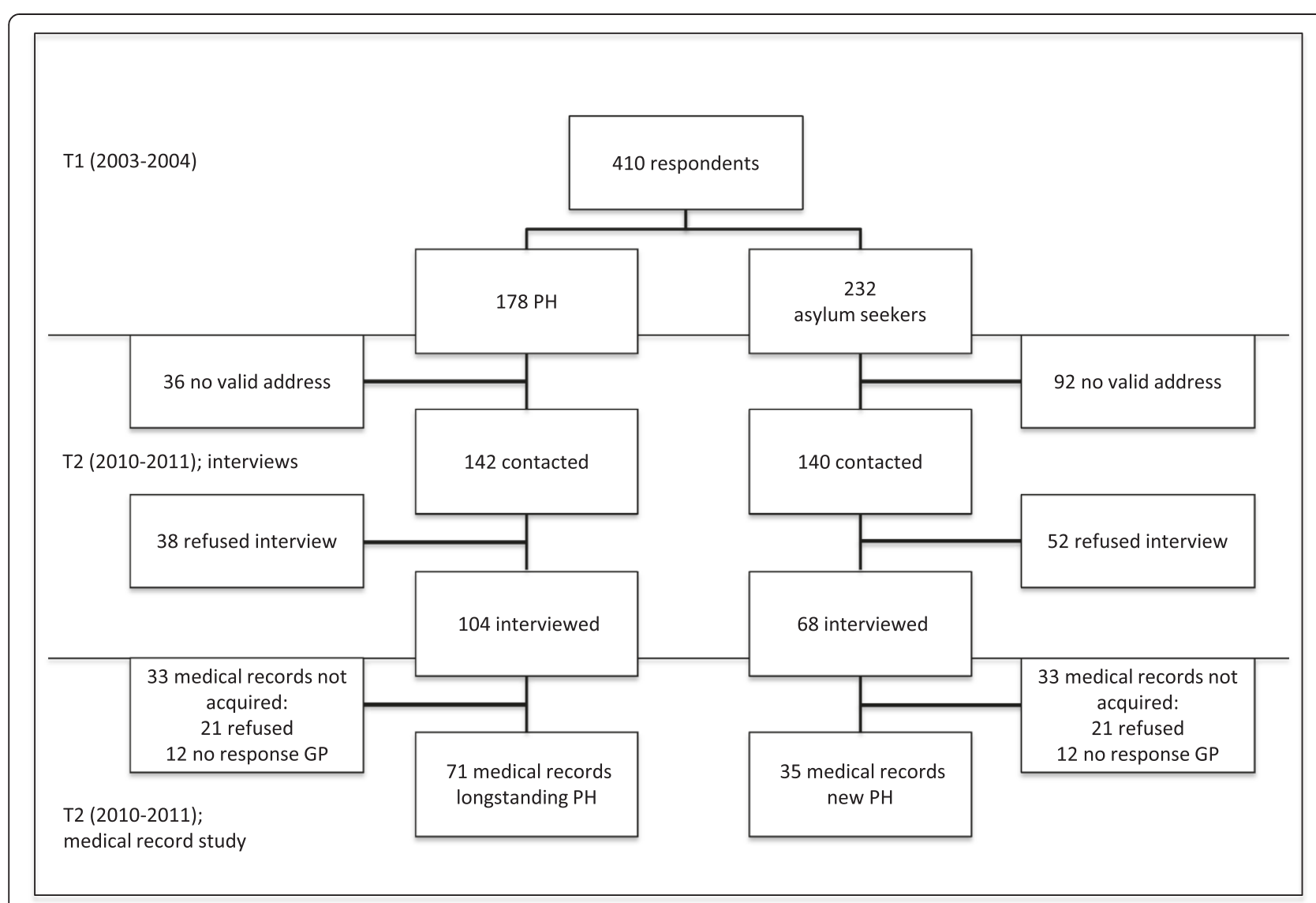

Figure 1 Flowchart of respondents throughout the two waves of the study. $\mathrm{T} 1$ had a total of $\mathrm{N}=410$ respondents, at $\mathrm{T} 2$ (the time of this study) 172 respondents participated in the interviews. 106 medical records were collected. PH = residence permit holders.

was pre-tested in a panel with key-figures from several ethnical groups, and a random sample of respondents in this study. In the interview respondents were questioned about their health and healthcare utilisation. This included a list of common conditions in medical and common language.

\section{Socio-demographic variables}

Socio-demographic variables included in the presented analyses are: age; gender; country of birth; and educational level ('none'; 'religious school or primary school'; 'secondary school'; 'higher education'; and 'vocational training and university'). Length of time in the Netherlands since receiving the permit was also recorded.

\section{GP's medical records}

- Recognition of common mental disorders The presence of a CMD was established during the interview using the Hopkins Symptom Check List for depression and anxiety (HSCL-25) and the Harvard Trauma Questionnaire for PTSD (HTQ); 
both questionnaires are validated for use in family practice and within several refugee groups [23-26]. However, the validity and reliability of the translations of these instruments (Dari, Pashto, Farsi and Somali) has not been tested in the population included in this study. We applied widely used cut-off points of 1.75 for the HSCL-25 or 2.5 for the HTQ.

- Chronic non-communicable diseases We reviewed medical records to identify patients with DMII and HT. A respondent was considered to have DMII when DMII was found in the problem list and/or the consultations, and/or when an anti-diabetic agent was prescribed.

\section{Quality of healthcare}

- GP recognition of CMD GP recognition was calculated as the number of $\mathrm{CMD}$ cases registered in the medical record compared to those found in the interviews.

- Patient awareness of DMII and HT Patient awareness of DMII and HT was scored as the percentage of subjects with DMII or HT diagnosed by the GP who reported their conditions in the interview. Participants were explicitly asked to indicate if they had a chronic condition using a list of chronic conditions which included DMII and HT. Patient awareness of DMII and HT were recorded separately.

- GPs' guideline adherence To evaluate GPs' guideline adherence, we used existing quality indicators based on the guidelines of the Dutch College of General Practitioners [27]. Table 1 shows a summary of these indicators.

- Assessment of guideline adherence in CMD used a set of indicators used in previous studies on guideline adherence in treatment of CMD [28-30] and was defined as: 1) at least five additional GP consultations within the same illness episode, 2) and/or short/long-term prescription of antidepressants, 3) and/or a referral to a mental healthcare specialist.

- Guideline adherence in DMII care was defined as compliance with at least four of the following eight rules [31], including testing in the past year of: 1) HbA1c; 2) serum LDL cholesterol; 3) plasma creatinine level; 4) proteinuria; 5) blood pressure measurement; 6) weight; 7) a foot examination; and 8) registration of a smoking habit. We used a strict scoring system of quality indicators (e.g. when "lab done" was noted in the record without specification, the quality indicators HbAlc, serum LDL cholesterol and plasma creatinine were scored as negative). To avoid an underestimation of guideline adherence, we chose a lenient cut-off value of 4 out of 8 criteria.
- Guideline adherence in HT care was defined as compliance with at least three of the following five rules [32] based on the GP's attention paid in the past year to: 1) (compliance with) therapy; 2) smoking behaviour (in case of current smoking or history of smoking); 3) blood pressure measurement; 4) weight; and 5) lifestyle or modification thereof (e.g. physical activity advice, low salt intake, alcohol reduction).

\section{Statistical analysis}

Descriptive statistics were used to present characteristics of the study groups, compared to characteristics of nonresponders, and to evaluate GP recognition of CMD, patient awareness of chronic health problems (DMII and HT) and guideline adherence in all disorders. Group differences were tested using Fishers' exact test for categorical data and an independent t-test for continuous data. All statistical tests were performed as two-tailed and $\mathrm{p}<0.05$ was considered statistically significant.

Statistical analyses were performed using SPSS 19.0 for Windows.

\section{Ethics}

Our project was sponsored by the GGD Nederland (Association of Community Health Services in the Netherlands). According to Dutch law, this study was exempt of formal medical-ethical approval but because of the vulnerable legal position of asylum seekers [and refugees] formal approval was obtained before the first wave. Before the interview at $\mathrm{T} 2$ informed consent was obtained from all respondents.

\section{Results}

Table 2 shows the characteristics of these 172 refugees, divided into groups for which we did and did not acquire a medical record. There were no significant differences between these groups, except that Somali refugees were underrepresented in the group with a medical record, i.e. $35 \%$ of the Somali patients did not give permission to collect their medical records, compared to $18 \%$ of the Afghan and $13 \%$ of the Iranian participants.

Of all the 172 refugees participating in the interviews, the prevalence of CMD (anxiety, depression and PTSD), DMII and HT identified in the interview was $34.9 \%$ (60/172), $17 \%$ (29/172) and 18\% (31/172), respectively.

\section{GP recognition of CMD}

Of the 106 respondents for whom we had medical records, 37 (35\%) had symptoms of CMD during the interview. Of these 37 respondents, the GP recognized a CMD in 18 (49\%). Of the remaining 69 respondents, a further $6(9 \%)$ were identified as having a CMD in the 
Table 1 Indicators for guideline adherence used in our study

\begin{tabular}{|c|c|}
\hline \multirow[t]{3}{*}{ CMD: } & 1) At least five additional GP consultations within the same illness episode \\
\hline & 2) And/or short/long-term prescription of antidepressants \\
\hline & 3) And/or a referral to a mental healthcare specialist. \\
\hline \multirow[t]{9}{*}{ DMII: } & Compliance with at least four of the following eight rules, including testing in the past year \\
\hline & 1) $\mathrm{HbA} 1 \mathrm{c}$ \\
\hline & 2) Serum LDL cholesterol \\
\hline & 3) Plasma creatinine level \\
\hline & 4) Proteinuria \\
\hline & 5) Blood pressure measurement \\
\hline & 6) Weight \\
\hline & 7) A foot examination \\
\hline & 8) Registration of a smoking habit. \\
\hline \multirow[t]{6}{*}{ HT: } & Compliance with at least three of the following five rules based on the GP's attention paid in the past year to \\
\hline & 1) (Compliance with) therapy \\
\hline & 2) Smoking behaviour (in case of current smoking or history of smoking) \\
\hline & 3) Blood pressure measurement \\
\hline & 4) Weight \\
\hline & 5) Lifestyle or modification thereof \\
\hline
\end{tabular}

medical record, although they were not identified as having a CMD diagnosis in the interview (Table 3 ).

\section{Patient awareness of DMII or HT}

Of the 106 respondents with an available medical record, 30 patients were documented to by the GP as having either DMII or HT. Of these 30 patients, 24 (80\%) indicated awareness of their condition (Table 4). Of the 16 patients documented by the GP as having DMII, 15 (94\%) indicated awareness of their condition. All refugees reporting DMII in the interview had a DMII diagnosis listed in their medical record. Of the 14 patients documented by the GP as having HT, 9 (64\%) indicated awareness of their condition. Ninety-two respondents were not documented by the GP as having HT. Of these, 7 (8\%) respondents reported to have HT during the interview.

\section{Guideline adherence}

Of the 54 refugees with a GP-diagnosed chronic disorder listed in the medical record, 35 (65\%) were treated according to healthcare guidelines. Of the 24 refugees with a CMD diagnosed by the GP, 17 (71\%) received guideline recommended care. Of the 30 refugees with DMII or HT, 18 (60\%) received guideline recommended care: $10 / 16(63 \%)$ for DMII and $8 / 14$ (57\%) for HT, respectively.

\section{Discussion}

Main findings

In this study, the GP recognition rate for CMD was $49 \%$. Patient awareness for the chronic non-communicable diseases was $80 \%$ ( $94 \%$ for DMII and $64 \%$ for HT). The GPs' adherence to guidelines for CMD, DMII and HT was $65 \%$. All these percentages are similar to those found in the general Dutch population [10,17,29,33-35].

\section{Strengths and limitations}

A strength of this study is the combination of interviews and medical records as data source. These two sources together provide a more comprehensive view on the process of healthcare provision by the GP, from GP recognition to patient awareness, to guideline adherence. To our knowledge, this is the first study focusing on healthcare for refugees living in a Western country for a longer period of time. Also, our analyses were conditionspecific rather than analysing general GP care, which allows a more focussed quality assessment of GP care.

This study also has some limitations. First, the results may be hampered by the small sample size, which often occurs in research on refugees. The prevalence of HT in the respondent group was lower than expected based on literature; this might be because healthy participants were more inclined to give permission to collect their medical records.

Also, in the present study, the refugees had lived in the Netherlands for a considerable period of time, had good command of the Dutch language, and had a relatively high education level. Patients with higher health skills may be more inclined to participate in research [36,37], which may explain these high percentages of patient awareness. These factors might limit the generalisability of these results to other, or more recent, groups 
Table 2 Characteristics of the participants $(n=172)$ with $(n=106)$ and without $(n=66)$ an available medical record

\begin{tabular}{|c|c|c|c|}
\hline & $\begin{array}{l}\text { Medical } \\
\text { record } \\
(n=106)^{1}\end{array}$ & $\begin{array}{l}\text { No medical } \\
\text { record }(n=66)^{1}\end{array}$ & $\mathrm{p}$-value \\
\hline Age in years: mean (SD) & $46.4(12)$ & $44.4(13)$ & 0.345 \\
\hline Gender (female): n (\%) & $51(48 \%)$ & $37(56 \%)$ & 0.311 \\
\hline $\begin{array}{l}\text { Time since permit in years: } \\
\text { median (range) }\end{array}$ & $10(1-26)$ & $8.5(1-23)$ & 0.822 \\
\hline \multicolumn{4}{|l|}{ Country of origin: n (\%) } \\
\hline - Afghanistan & $50(47 \%)$ & $32(49 \%)$ & \\
\hline - Iran & $45(43 \%)$ & $18(27 \%)$ & \\
\hline - Somalia & $11(10 \%)$ & $16(24 \%)$ & 0.023 \\
\hline Education: n (\%) & $(n=105)$ & $(n=64)$ & \\
\hline - Low & $19(18 \%)$ & $13(20 \%)$ & \\
\hline - Intermediate & $26(25 \%)$ & $14(22 \%)$ & \\
\hline - High & $60(57 \%)$ & $37(58 \%)$ & 0.884 \\
\hline \multicolumn{4}{|l|}{ Prevalence } \\
\hline $\begin{array}{l}-\underset{(n, \%)}{\text { PTSD }}(\text { HTQ score > 2.5) } \\
(n, \%)\end{array}$ & $17(16 \%)$ & $9(14 \%)$ & 0.669 \\
\hline $\begin{array}{l}\text { - Anxiety and/or Depression } \\
\text { (HSCL-25 > 1.75) }\end{array}$ & $37(35 \%)$ & $23(35 \%)$ & 0.994 \\
\hline $\begin{array}{l}\text { - CMD (PTSD, depression or } \\
\text { anxiety) }\end{array}$ & $37(35 \%)$ & $23(35 \%)$ & 0.994 \\
\hline $\begin{array}{l}\text { - Diabetes type II (according } \\
\text { to interview) }\end{array}$ & $14(13 \%)$ & $15(23 \%)$ & 0.352 \\
\hline $\begin{array}{l}\text { - Hypertension (according } \\
\text { to interview) }\end{array}$ & $16(15 \%)$ & $15(23 \%)$ & 0.188 \\
\hline
\end{tabular}

PTSD = Post-Traumatic Stress Disorder, $\mathrm{HTQ}=$ Harvard Trauma Questionnaire, $\mathrm{HSCL}=$ Hopkins Symptom Checklist, $\mathrm{CMD}=$ Common Mental Disorder.

${ }^{1}$ Proportion's denominator, unless indicated otherwise.

of refugees. However, CMD-rates in this subgroup of 172 respondents ( $47 \%$ in 2003 ) were comparable to the overall rates found in the first wave of the study (48\%; $\mathrm{N}=410$ ), so the respondents in the second wave do not seem to differ from the respondents in the first wave [38].

In addition, the translations of the survey tools we used in the diagnoses of CMD were not validated which may have implications for the diagnosis of CMD in this

Table 3 GPs' recognition of chronic mental disorders $(C M D)^{1}$; number of cases of CMD identified in the interview and as registered by the GP in the medical record

\begin{tabular}{llll}
\hline & $\begin{array}{l}\text { CMD diagnosis } \\
\text { in medical record }\end{array}$ & $\begin{array}{l}\text { No diagnosis of } \\
\text { CMD in medical } \\
\text { record }\end{array}$ & $\begin{array}{l}\text { Total } \\
\text { patients }\end{array}$ \\
\hline $\begin{array}{l}\text { CMD measured } \\
\text { in interview }\end{array}$ & $18(49 \%)$ & $19(51 \%)$ & 37 \\
$\begin{array}{l}\text { No CMD measured } \\
\text { in interview }\end{array}$ & $6(9 \%)$ & $63(91 \%)$ & 69 \\
Total & 24 & 72 & 106 \\
\hline
\end{tabular}

${ }^{1}$ PTSD, depression or anxiety.
Table 4 Patient awareness of diabetes type 2 (DMII) and hypertension (HT) among resettled refugees $(n=106)$

\begin{tabular}{|c|c|c|c|}
\hline & $\begin{array}{l}\text { Diagnosis } \\
\text { registered in } \\
\text { medical record }\end{array}$ & $\begin{array}{l}\text { No diagnosis } \\
\text { registered in } \\
\text { medical record }\end{array}$ & $\begin{array}{l}\text { Total } \\
\text { patients }\end{array}$ \\
\hline $\begin{array}{l}\text { DMIl reported in } \\
\text { interview }\end{array}$ & $15(94 \%)$ & $0(0 \%)$ & 15 \\
\hline $\begin{array}{l}\text { DMII not reported } \\
\text { in interview }\end{array}$ & $1(6 \%)$ & $90(100 \%)$ & 91 \\
\hline Total & 16 & 90 & 106 \\
\hline HT reported in interview & $9(64 \%)$ & $7(8 \%)$ & 16 \\
\hline $\begin{array}{l}\text { HT not reported in } \\
\text { interview }\end{array}$ & $5(36 \%)$ & $85(92 \%)$ & 90 \\
\hline Total & 14 & 92 & 106 \\
\hline
\end{tabular}

Number of self-reported cases from the interviews and diagnoses as registered by the GP.

study. This could have possibly resulted in false positive and/or false negative case findings.

Finally, the set of adherence indicators we used for CMD was rather loose compared to the adherence indicators for DMII and HT; they make no distinction between treatments. Every treatment (therapy or antidepressants) or more than five GP observations is seen as guideline adherence. This ignores the (over) prescription of antidepressants where psychotherapy would be optimal. Also, it is possible that a patient had over five appointments with the GP several in which a patient is returning because they do not feel their needs have been met, rather than pro-active follow-up or intervention by the GP.

\section{GP recognition rate of common mental disorders}

In previous research, the GP recognition rates for CMD in the general Dutch population are below $50 \%$ depending on the definition used $[29,33,35]$. Our study shows a similar recognition rate of $49 \%$.

\section{Patient awareness of chronic diseases}

In the present study, the $80 \%$ patient awareness rate for DMII and HT was much higher than reported in other studies, ranging from $29-60 \%$ among Dutch patients [34], whereas the reported awareness of HT (64\%) was similar to that in other ethnic populations living in the Netherlands [17]. No other studies were found reporting on awareness among patients with DMII. While awaiting confirmation in future studies, these figures are reassuring.

\section{Guideline adherence by GPs}

In this study, the GP guideline adherence for refugee patients was found to be consistent with other reports of guidelines adherence in the Netherlands. A systematic review on guideline adherence in the Netherlands reported guideline concordant care for $27-58 \%$ of patients 
with a CMD, $41-59 \%$ for those with DMII, and 60\% in the HT group [10]. This latter study suggests that no specific barriers exist in the use of GP services for refugees with chronic conditions compared to the Dutch general population.

\section{International/European comparison}

Unfortunately, we found no international studies on the quality of primary care for resettled refugees in Western countries. To our knowledge, ours is the first study focusing on healthcare for refugees living in a Western country for a longer period of time. International studies on quality of care in minorities and refugees show that these groups are less likely to receive adequate care $[11,18,19]$. We can only speculate why our study shows a comparable quality of care to the native Dutch population in our population of resettled refugees. Our refugee population had lived in the Netherlands for a considerable period of time, had good command of the Dutch language, and had a relatively high education level. Patients with higher health skills in general are more inclined to participate in research. This can create a selection bias and explain our results. Another possibility is that barriers experienced by more recently arrived refugees (e.g. affordability, poor health literacy and understanding of the health system, medical mistrust, discrimination, and linguistic and cultural factors) [39] reduce through time. Refugees learn the language, culture and get to know the Dutch health care system. They build a relationship with their GP, which lowers mistrust.

Our results are of interest for all countries with a primary care-based healthcare system and we recommend further research on this resettled population, especially in view of the constant flow of refugees over time.

\section{Implications}

The results of this study indicate that GP recognition of CMD, patient awareness of chronic non-communicable diseases, and guideline concordant care by the GP for resettled refugees with chronic health problems, is neither better nor worse than the care for ethnic Dutch patients. Nevertheless, GP awareness of the high prevalence of CMD (and especially PTSD) in this population could be further improved, together with overall patient awareness of HT.

Future research should combine assessment of primary healthcare provision for (resettled) refugees, native Dutch and other Dutch ethnicities in a matched controlled study to further explore known barriers and interventions needed.

\section{Conclusion}

Our study shows that awareness among resettled refugees of GP diagnosed DMII and HT is high, whereas GP recognition of CMD and overall guideline adherence are moderate.

Recognition, awareness and guideline adherence were in concordance with that of the general Dutch population. However, GP recognition and patient awareness of CMD and HT are not yet optimal in either the refugee or the general patient population.

\section{Competing interests}

The authors declare that they have no competing interests.

\section{Authors' contributions}

MM, ML, MS, AG, WD and ME conceived the study. MM developed the protocol. ML and ME closely supervised the protocol development. MS contributed to the protocol development. MM retrieved the data from medical records. MM analysed the data, interpreted the results and wrote the first draft of the manuscript. ML and ME supervised the analysis and interpretation of the results. All authors participated in reviewing and editing of various drafts of the manuscript and they all read and approved the final manuscript.

\section{Acknowledgements}

We would like to thank Sandra Mul for coordinating the data collection.

\section{Author details}

${ }^{1}$ Department of Public Health, Academic Medical Center, University of Amsterdam, Amsterdam, The Netherlands. ${ }^{2}$ Department of Clinical Epidemiology, Biostatistics and Bioinformatica, Academic Medical Centre, University of Amsterdam, Amsterdam, The Netherlands. ${ }^{3}$ Epi Result, Louis Trichardt, South Africa. ${ }^{4}$ NIVEL (Netherlands Institute for Health Services Research), Utrecht, The Netherlands. ${ }^{5}$ Faculty of Social and Behavioural Sciences, University of Amsterdam, Amsterdam, The Netherlands. ${ }^{6}$ National Knowledge and Advisory Center on Migrants, Refugees and Health (Pharos), Utrecht, The Netherlands.

Received: 25 April 2014 Accepted: 19 September 2014

Published: 23 September 2014

\section{References}

1. Washington DC: United Nations Refugee Agency (UNHCR): Statistical Overview of Asylum Applications Lodged in Europe and Selected Non-European Countries. [http://www.unhcr.org/cgi-bin/texis/vtx/page? page $=49$ e48eca6\&submit=GO\#]

2. Gerritsen AA, Bramsen I, Deville W, van Willigen LH, Hovens JE, van der Ploeg HM: Physical and mental health of Afghan, Iranian and Somali asylum seekers and refugees living in the Netherlands. Soc Psychiatry Psychiatr Epidemiol 2006, 41:18-26.

3. Marcus M, Taghi Yasamy M, van Ommeren M, Chisholm D, Saxena S: Depression; A Global Public Health Concern. WHO Department of Mental Health and Substance Abuse. [http://www.who.int/mental_health/ management/depression/who_paper_depression_wfmh_2012.pdf]

4. Kessler RC, Aguilar-Gaxiola S, Alonso J, Chatterji S, Lee S, Ormel J, Ustün TB, Wang PS: The global burden of mental disorders: an update from the WHO World Mental Health (WMH) surveys. Epidemiol Psychiatr Soc 2009, 18:23-33.

5. de Vries GJ, Olff M: The lifetime prevalence of traumatic events and posttraumatic stress disorder in the Netherlands. J Trauma Stress 2009, 22:259-267.

6. Fazel M, Wheeler J, Danesh JL: Prevalence of serious mental disorder in 7000 refugees resettled in western countries: a systematic review. Lancet 2005, 365:1309-1314.

7. Steel Z, Chey T, Silove D, Marnane C, Bryant RA, van Ommeren M: Association of torture and other potentially traumatic events with mental health outcomes among populations exposed to mass conflict and displacement: a systematic review and meta-analysis. JAMA 2009, 302:537-549.

8. Carlson EB, Rosser-Hogan R: Trauma experiences, posttraumatic stress, dissociation, and depression in Cambodian refugees. Am J Psychiatry 1991, 148:1548-1551. 
9. Geltman PL, Dookeran NM, Battaglia T, Cochran J: Chronic disease and its risk factors among refugees and asylees in Massachusetts, 2001-2005. Prev Chronic Dis 2010, 7:A51.

10. Bloemendal EWJW, Harmsen M, Mistiaen P: Naleving van Nederlandse richtlijnen; een systematische review. Utrecht/Nijmegen: NIVEL, 2011 [http://www.nivel.nl/sites/default/files/bestanden/Rapport-NalevingNederlandse-richtlijnen.pdf]

11. Kirmayer LJ, Weinfeld M, Burgos G, du Fort GG, Lasry JC, Young A: Use of health care services for psychological distress by immigrants in an urban multicultural milieu. Can J Psychiatry 2007, 52:295-304.

12. Yanni EA, Naoum M, Odeh N, Han P, Coleman M, Burke H: The health profile and chronic diseases comorbidities of US-bound Iraqi refugees screened by the International Organization for Migration in Jordan: 2007-2009. J Immigr Minor Health 2013, 15:1-9.

13. Yun K, Hebrank K, Graber LK, Sullivan MC, Chen I, Gupta J: High prevalence of chronic non-communicable conditions among adult refugees: implications for practice and policy. J Community Health 2012, 37:1110-1118.

14. Kumar BN, Selmer R, Lindman AS, Tverdal A, Falster K, Meyer HE: Ethnic differences in SCORE cardiovascular risk in Oslo, Norway. Eur J Cardiovasc Prev Rehabil 2009, 16:229-234.

15. Kinzie JD, Riley C, McFarland B, Hayes M, Boehnlein J, Leung P, Adams G: High prevalence rates of diabetes and hypertension among refugee psychiatric patients. J Nerv Ment Dis 2008, 196:108-112.

16. Blokstra A, Venmans LMA, Holleman P, van der Schouw YT, Smit HA, Verschuren WMM: Nederland de Maat Genomen, 2009-2010; Monitoring van risicofactoren in de algemene bevolking. 2011, RIVM Rapport 260152001/2011.

17. Agyemang C, de Munter J, van Valkengoed I, van den Born BJ, Stronks K Gender disparities in hypertension among different ethnic groups in Amsterdam, The Netherlands: the SUNSET study. Am J Hypertens 2008, 21:1001-1006

18. Agyemang C, Nicolaou M, Boateng L, Dijkshoorn H, van de Born BJ, Stronks K. Prevalence, awareness, treatment, and control of hypertension among Ghanaian population in Amsterdam, the Netherlands: the GHAIA study. Eur J Prev Cardiol 2013, 20:938-946.

19. Wieland ML, Morrison TB, Cha SS, Rahman AS, Chaudhry R: Diabetes care among Somali immigrants and refugees. J Community Health 2012, 37:680-684

20. Donabedian A: The quality of care how can it be assessed? JAMA 1988, 260:1743-1748.

21. Gerritsen AA, Bramsen I, Deville W, van Willigen $L H$, Hovens JE, van der Ploeg $H M$ : Health and health care utilisation among asylum seekers and refugees in the Netherlands: design of a study. BMC Public Health 2004, 4:7.

22. Lamkaddem M, Stronks K, Deville WD, Olff M, Gerritsen AAM, Essink-Bot ML: Course of post-traumatic stress disorder and health care utilisation among resettled refugees in the Netherlands. BMC Psychiatry 2014, 14:90.

23. Mollica RF, Wyshak G, de Marneffe D, Khuon F, Lavelle J: Indochinese versions of the Hopkins Symptom Checklist-25: a screening instrument for the psychiatric care of refugees. Am J Psychiatry 1987, 144:497-500.

24. Hesbacher PT, Rickels K, Morris RJ, Newman H, Rosenfeld H: Psychiatric illness in family practice. Eur J Prev Cardiol 1980, 41:6-10.

25. Mollica RF, Caspi-Yavin Y, Bollini P, Truong T, Tor S, Lavelle J: The Harvard Trauma Questionnaire. Validating a cross-cultural instrument for measuring torture, trauma, and posttraumatic stress disorder in Indochinese refugees. J Nerv Ment Dis 1992, 180:111-116.

26. Tinghog P, Al-Saffar S, Carstensen J, Nordenfelt L: The association of immigrant- and non-immigrant-specific factors with mental ill health among immigrants in Sweden. Int J Soc Psychiatry 2010, 56:74-93.

27. Dutch College of General Practitioners. [https://www.nhg.org/nhgstandaarden]

28. Fassaert T, Nielen M, Verheij R, Verhoeff A, Dekker J, Beekman A, de Wit M: Quality of care for anxiety and depression in different ethnic groups by family practitioners in urban areas in the Netherlands. Gen Hosp Psychiatry 2010, 32:368-376

29. Smolders M, Laurant M, Verhaak P, Prins M, van Marwijk H, Penninx B, Wensing M, Grol R: Adherence to evidence-based guidelines for depression and anxiety disorders is associated with recording of the diagnosis. Gen Hosp Psychiatry 2009, 31:460-469.

30. Prins MA, Verhaak PF, Smolders M, Laurant MG, van der Meer $K$, Spreeuwenberg P, van Marwijk HW, Penninx BW, Bensing JM: Patient factors associated with guideline-concordant treatment of anxiety and depression in primary care. J Gen Intern Med 2010, 25:648-655.
31. Spigt M, Stefens $C$, Passage $D$, Van Amelsvoort $L$, Zwietering $P$ : The relationship between primary health care organization and quality of diabetes care. Eur J Gen Pract 2009, 15:212-218.

32. Frijling $\mathrm{BD}$, Lobo $\mathrm{CM}$, Hulscher $\mathrm{ME}$, van Drenth $\mathrm{BB}$, Braspenning JC, Prins $\mathrm{A}$, van der Wouden JC, Grol RP: Provision of information and advice in cardiovascular care: clinical performance of general practitioners. Patient Educ Couns 2002, 48:131-137.

33. Joling KJ, van Marwijk HW, Piek E, van der Horst HE, Penninx BW, Verhaak P, van Hout HP: Do GPs' medical records demonstrate a good recognition of depression? A new perspective on case extraction. J Affect Disord 2011, 133:522-527.

34. Janssen EH, van de Ven PM, Terluin B, Verhaak PF, van Marwijk HW, Smolders M, van der Meer K, Penninx BW, van Hout HP: Recognition of anxiety disorders by family physicians after rigorous medical record case extraction: results of the Netherlands Study of Depression and Anxiety. Gen Hosp Psychiatry 2012, 34:460-467.

35. Scheltens T, Bots ML, Numans ME, Grobbee DE, Hoes AW: Awareness, treatment and control of hypertension: the 'rule of halves' in an era of risk-based treatment of hypertension. J Hum Hypertens 2007, 21:99-106.

36. Schmotzer GL: Barriers and facilitators to participation of minorities in clinical trials. Ethn Dis 2012, 22:226-230.

37. Ross S, Grant A, Counsell C, Gillespie W, Russell I, Prescott R: Barriers to participation in randomised controlled trials: a systematic review. J Clin Epidemiol 1999, 52:1143-1156.

38. Lamkaddem M, Essink-Bot ML, Stronks K: Gevlucht gezond II; ontwikkelingen in gezondheid en zorggebruik van vluchtelingen in Nederland. 2013, [http://www.ggdkennisnet.nl/?file $=13188 \& \mathrm{~m}=$ 1370254028\&action=file.download]

39. Hadgkiss EJ, Renzaho AM: The physical health status, service utilisation and barriers to accessing care for asylum seekers residing in the community: a systematic review of literature. Aust Health Rev 2014, 38:142-159.

doi:10.1186/1471-2296-15-160

Cite this article as: van Melle et al:: Quality of primary care for resettled refugees in the Netherlands with chronic mental and physical health problems: a cross-sectional analysis of medical records and interview data. BMC Family Practice 2014 15:160.

\section{Submit your next manuscript to BioMed Central and take full advantage of:}

- Convenient online submission

- Thorough peer review

- No space constraints or color figure charges

- Immediate publication on acceptance

- Inclusion in PubMed, CAS, Scopus and Google Scholar

- Research which is freely available for redistribution 